\title{
Numerical study of the Middle Adriatic coastal waters' sensitivity to the various air pressure travelling disturbances
}

\author{
I. Vilibić \\ Institute of Oceanography and Fisheries, Šetalište I. Meštrovića 63, 21000 Split, Croatia \\ Received: 27 May 2005 - Revised: 18 October 2005 - Accepted: 20 October 2005 - Published: 23 December 2005
}

\begin{abstract}
The paper documents resonant coupling between an air pressure travelling disturbance and the Middle Adriatic coastal waters, examined theoretically by using a barotropic numerical model and then comparing the model to the observed events. The model is forced first with a cosine and box air pressure disturbance travelling with a constant speed and direction but varying its eulerian period/duration, whereas the sensitivity to the disturbance speed is examined by varying it, keeping all the other parameters constant. Larger resonant transfer of energy is documented for shorter disturbances and for the box versus cosine variation, especially in the high-frequency domain. Bands of enlarged sea level amplification are found in front of Stari Grad Bay (6.7 and $11.0 \mathrm{~min}$ ) close to its natural modes $(6.1$ and $10.6 \mathrm{~min})$, which may be a reason for the very large amplification and sporadic severe floods observed at the inner bay area. The lack of coincidence in the Stari Grad and Vela Luka observed floods may be partially a result of different disturbance speeds and energy transfer rates due to various depths off the bays, yet some additional factors (basin shape, real disturbance energy, disturbance direction) should be examined in the future.
\end{abstract}

Keywords. Oceanography: General (Numerical modeling) - Oceanography: Physical (Air-sea interactions; Tsunamis and storm surges)

\section{Introduction}

An exceptional flood event, which occurred in June 2003 in the middle Adriatic coastal waters (Vilibić et al., 2004), generated by energetic atmospheric gravity waves travelling eastwards, enhanced the investigations of such very rare but vigorous events in the Adriatic Sea in which a resonant atmosphere-ocean energy transfer takes place at certain areas. High-frequency sea level oscillations reached $1.2 \mathrm{~m}$

Correspondence to: I. Vilibić

(vilibic@izor.hr) at the top of the Stari Grad Harbour, whereas severe currents $(>100 \mathrm{~cm} / \mathrm{s})$ swept out shell farms when resonantlygenerated waves reached the semi-enclosed Mali Ston Bay situated at the top of the basin. The last strong event occurred in June 1978 at Vela Luka, where 3-m high waves flooded a great part of the city (Hodžić, 1980; Orlić, 1980), but no flood events have been recorded in between, decreasing the interest for the scientific investigations of the events.

The phenomenon of resonant coupling between travelling gravity waves and the ocean is documented worldwide (Donn, 1959; Hibiya and Kajiura, 1982; Rabinovich, 1993; Dragani et al., 2002; Mercer et al., 2002). Due to its similarity to the tsunami waves (barotropic waves propagating in the whole water column), some authors call it meteotsunami (Defant, 1961; Rabinovich and Monserrat, 1998). Atmospheric gravity waves, which are manifested through highfrequency oscillations in air pressure, induce ocean waves which are dynamically multiplied at the depths where the speed of the air pressure disturbance is equal to the speed of long waves in the sea. This process is known as Proudman resonance, named after the classical paper by Proudman (1929). However, another effect is crucial to obtain exceptionally large oscillations at the top of the closed basins, that is the so-called harbour resonance, which represents basin natural oscillations - seiches - induced by incoming opensea waves. Both effects have been well documented and investigated in some parts of the Mediterranean Sea, such as the Balearic Islands (Tintore et al., 1988; Monserrat et al., 1991, 1998; Gomis et al., 1993; Garcies et al., 1996; Rabinovich et al., 1999) and Sicily (Candela et al., 1999). Furthermore, an additional sea level set-up may occur as a result of topographic constraints of a basin (Vilibić et al., 2004), edge waves around an island (Liu et al., 2002) or coupling between two adjacent inlets (Liu et al., 2003).

The Middle Adriatic flood event of June 2003 has been used to verify the nature of the event, as the great flood of Vela Luka in June 1978 is covered by a few low-precision measurements (Orlić, 1980). Numerical modelling has been used and verified on tide gauge data, but again no 


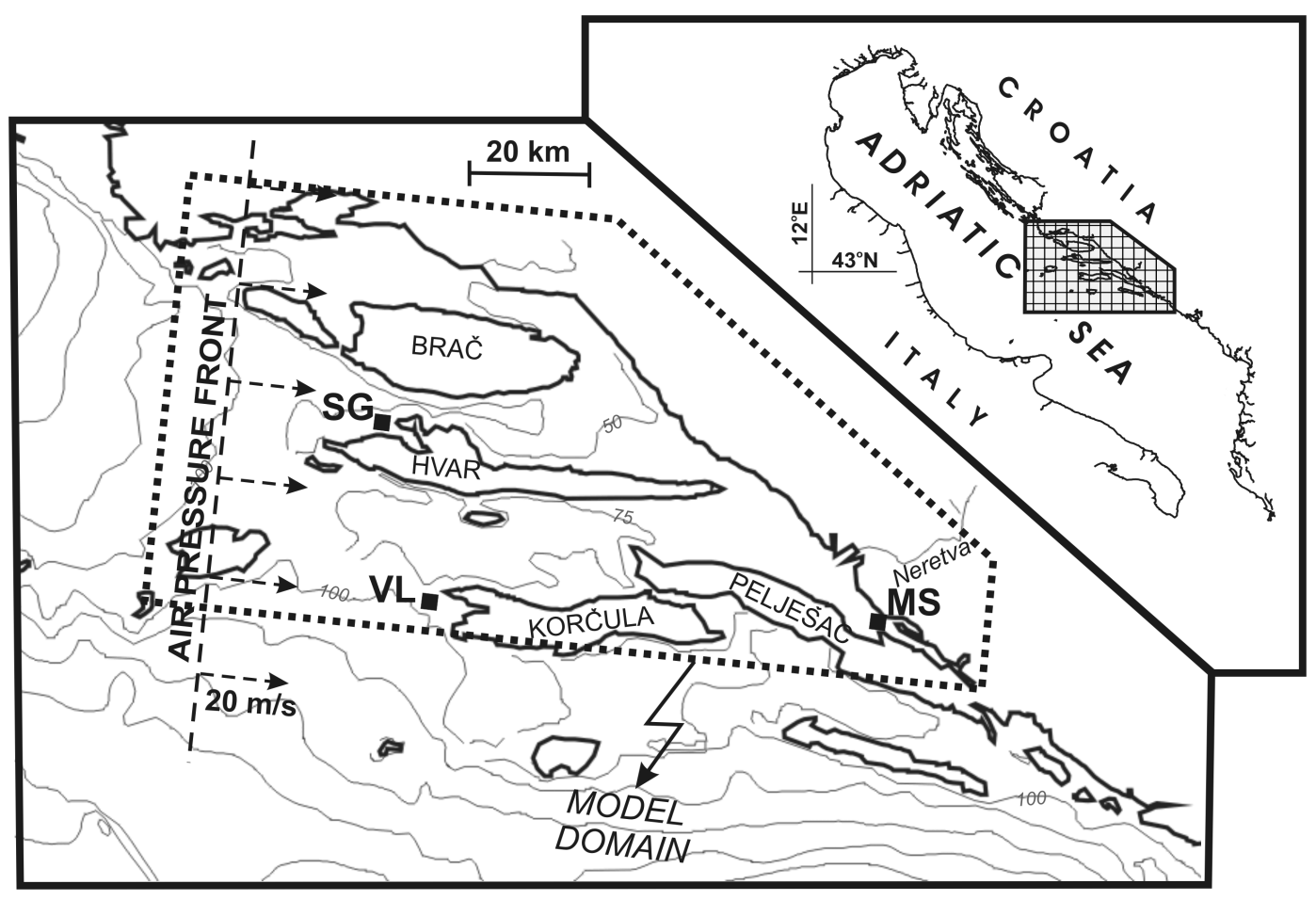

Fig. 1. Position and bathymetry of the eastern part of the middle Adriatic Sea. The domain of the numerical model is dashed, with grid points (rectangles) marked in front of Stari Grad (SG), Vela Luka (VL) and Mali Ston (MS) Bays. Speed and direction of the travelling air-pressure disturbance are shown, too.

measurements have been carried out in the most affected areas (Vilibić et al., 2004). However, the model has been in agreement with eyewitness reports, and therefore the nature of the event has been proven. A year later, in August 2004, another episode of strong sea level oscillations has been recorded in the area, but fortunately without flooding. As the travelling air pressure disturbance has a shape of the box function, different from the June 2003 event when a cosinelike disturbance occurred, and the August 2004 event was coupled with relatively strong alongshore winds, two questions arose: (i) why does the flooding only occur during some events, and (ii) which is the more generative force, wind or travelling air pressure disturbance? Vilibić et al. (2005) compared two events and demonstrated that the reason for the different energy versus frequency distribution is the difference in the energetics of the air pressure travelling disturbance box versus cosine disturbance. In addition, wind stress explained about $30 \%$ of the oscillations during the August 2004 event, whereas the rest had been assigned to the air pressure influence.

As the harbour resonance is excited by the open sea waves, which are predominantly generated by the Proudman resonance, the next step is to explore atmosphere-ocean energy transfer for documented travelling disturbances, but varying its parameters (period, duration, speed), in order to capture a variety of possible generation scenarios. Therefore, this paper will document the sensitivity of sea level oscillations in front of the most affected areas (Stari Grad, Vela Luka, Mali
Ston) generated by artificial travelling disturbances. The methodology will comprise barotropic numerical modelling of the area by 2DD model (Black, 1995), already used in two previous studies (Vilibić et al., 2004, 2005). The model and forcing will be described in Sect. 2; Sect. 3 will document various model runs and sea level characteristics off hot spots, being summarised and concluded in Sect. 4.

\section{Material and methods}

The eastern Middle Adriatic Sea is a complex bay system open to the west with a number of along-bay islands and channels (Fig. 1). The depth decreases from $100 \mathrm{~m}$ at the entrance to about $15 \mathrm{~m}$ in the inner part off Mali Ston Bay, with the ability to resonantly capture atmospheric gravity waves through a Proudman resonance travelling at a speed of 12 to $30 \mathrm{~m} / \mathrm{s}$. However, the most energetic events have been recorded with a speed of about $20 \mathrm{~m} / \mathrm{s}(22 \mathrm{~m} / \mathrm{s}$ in June 2003 , Vilibić et al., 2004, and $18 \mathrm{~m} / \mathrm{s}$ in August 2004, Vilibić et al., 2005). Cross-section areas are reduced by a decrease in both width and depth; therefore, it should be expected that any wave or disturbance propagating in the sea from the west to the east will be amplified at the bay head (Mali Ston Bay) due to a topographical effect.

The simulations of various gravity disturbances and their coupling with the coastal waters was undertaken using a two-dimensional, nonlinear, finite difference model 2DD developed by Black (1995). An explicit leapfrog solution is 
applied to solve the two-dimensional momentum and continuity equations, equipped with an air pressure term:

$$
\begin{aligned}
& \frac{\partial u}{\partial t}+u \frac{\partial u}{\partial x}+v \frac{\partial u}{\partial y}-f v= \\
& \quad-g \frac{\partial \zeta}{\partial x}-\frac{g u\left(u^{2}+v^{2}\right)^{1 / 2}}{C^{2}(d+\zeta)}-\frac{1}{\rho} \frac{\partial P}{\partial x}+A_{H}\left(\frac{\partial^{2} u}{\partial x^{2}}+\frac{\partial^{2} u}{\partial y^{2}}\right) \\
& \frac{\partial v}{\partial t}+u \frac{\partial v}{\partial x}+v \frac{\partial v}{\partial y}+f u= \\
& \quad-g \frac{\partial \zeta}{\partial y}-\frac{g v\left(u^{2}+v^{2}\right)^{1 / 2}}{C^{2}(d+\zeta)}-\frac{1}{\rho} \frac{\partial P}{\partial y}+A_{H}\left(\frac{\partial^{2} v}{\partial x^{2}}+\frac{\partial^{2} v}{\partial y^{2}}\right) \\
& \frac{\partial \zeta}{\partial t}+\frac{\partial}{\partial x}[(d+\zeta) u]+\frac{\partial}{\partial y}[(d+\zeta) v]=0,
\end{aligned}
$$

where $t$ is time, $u$ and $v$ are vertically averaged velocities in the $x$ and $y$ directions, $g$ is acceleration due to gravity $\left(9.81 \mathrm{~m} / \mathrm{s}^{2}\right), \zeta$ stands for sea level above a horizontal datum, $d$ marks the water depth below the datum, $f$ is the Coriolis parameter, $\rho\left(1028 \mathrm{~kg} / \mathrm{m}^{3}\right)$ and $\rho_{a}$ are the water and air density, respectively, $P$ denotes air pressure and $A_{H}$ is the horizontal eddy viscosity coefficient. Seabed frictional resistance $C$ is given by

$C=18 \log _{10}\left(0.37 h / z_{0}\right)$,

where $h$ is total water depth and $z_{0}$ is the roughness length (a level above the bed where velocity equals zero).

The model domain is originally developed for investigations of the tsunami event which occurred in the region (Herak et al., 2001), and used in the previous case studies by Vilibić et al. (2004, 2005) - see Fig. 1. Grid resolution is chosen to be $1 \mathrm{~km}$, altogether $139 \times 68$ grid cells. The simulations were carried out with time steps of $12 \mathrm{~s}$, in order to satisfy the stability criterion for the grid sizes and depths considered. Horizontal eddy viscosity coefficient $A_{H}$ is set to $75 \mathrm{~m}^{2} / \mathrm{s}$, bottom roughness $z_{0}$ to $0.003 \mathrm{~m}$, while a radiation condition was imposed at the open boundaries, together with additional smoothing and minimizing the reflection by applying sponge boundaries (Black, 1995). These numbers are taken from the referred case studies, where the model results were successfully calibrated on real sea level measurements.

The model is forced by an artificial travelling disturbance which propagates eastward along the domain with a speed of $V_{C}=20 \mathrm{~m} / \mathrm{s}$, as these values meet the observed ones during the flood events (Fig. 2). Therefore, these parameters will be set to constant values, whereas types and parameters of travelling disturbances will be varied. Two main types of the travelling air pressure disturbance will be considered: (i) cosine-like and (ii) box-like disturbances (Fig. 3), which were observed in the area. The air pressure field is set to a constant value before and after the passage of the disturbance. A number of model runs for each disturbance has been performed, changing the Eulerian period $T_{C}$ (for cosine ones) or duration $T_{B}$ (for box ones) from 0.5 to $4 \mathrm{~h}$ (Eulerian period is defined from the pressure series measured at a
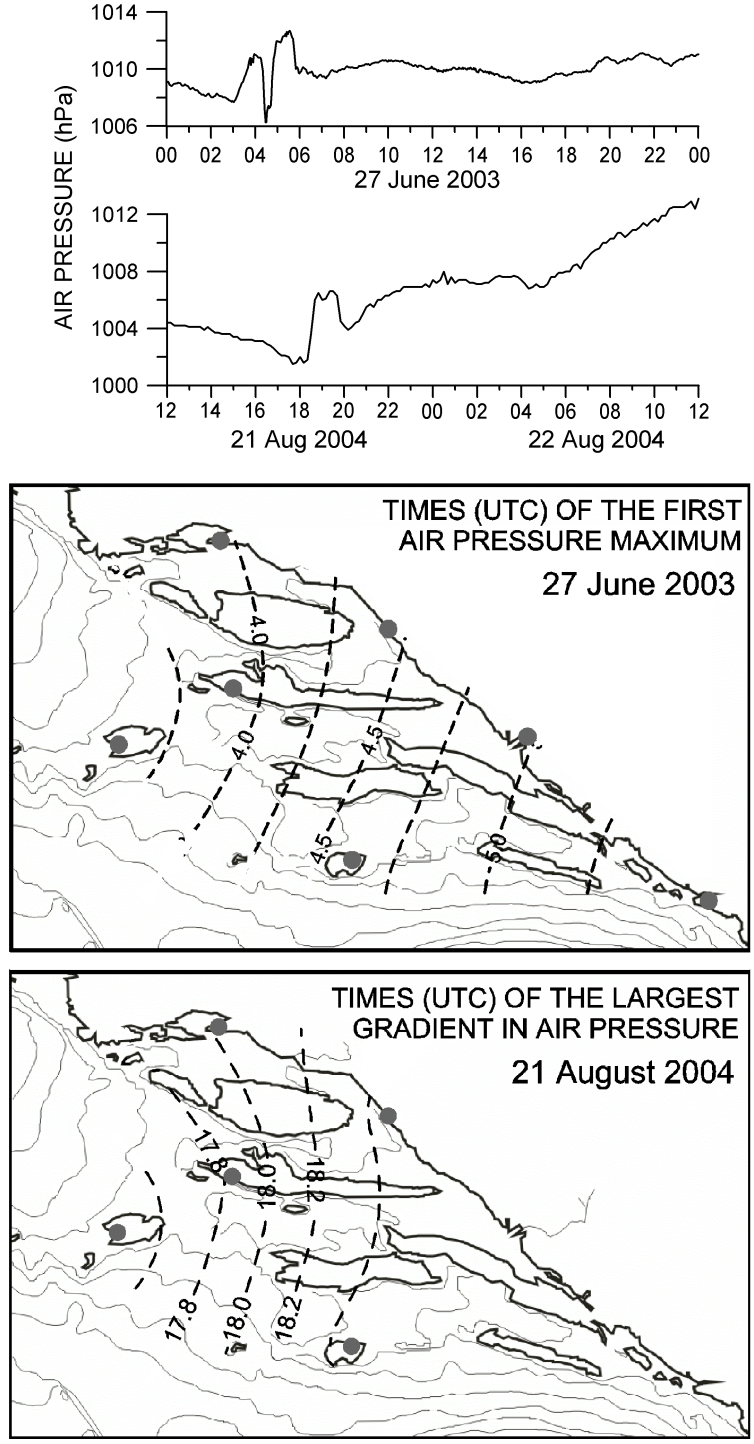

Fig. 2. Measured air pressure series on 27 June 2003 and 21-22 August 2004 (upper panel), and times of air pressure disturbance arrival as captured by the measurements (bottom panel, after Vilibić et al., 2004, 2005).

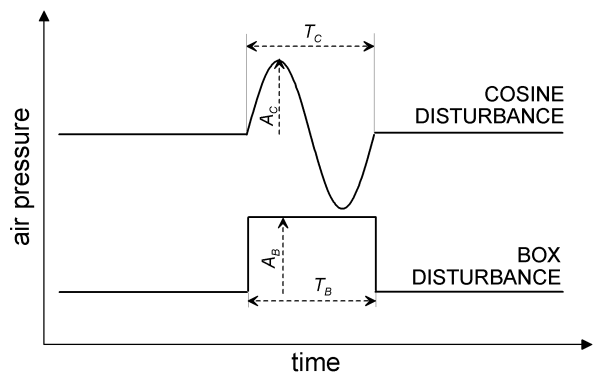

Fig. 3. Sketch of Eulerian time series for cosine and box travelling disturbances (bottom panel). $T_{C}$ and $T_{B}$ stand for the disturbance period/duration, and $A_{C}$ and $A_{B}$ represents their amplitude, respectively. 

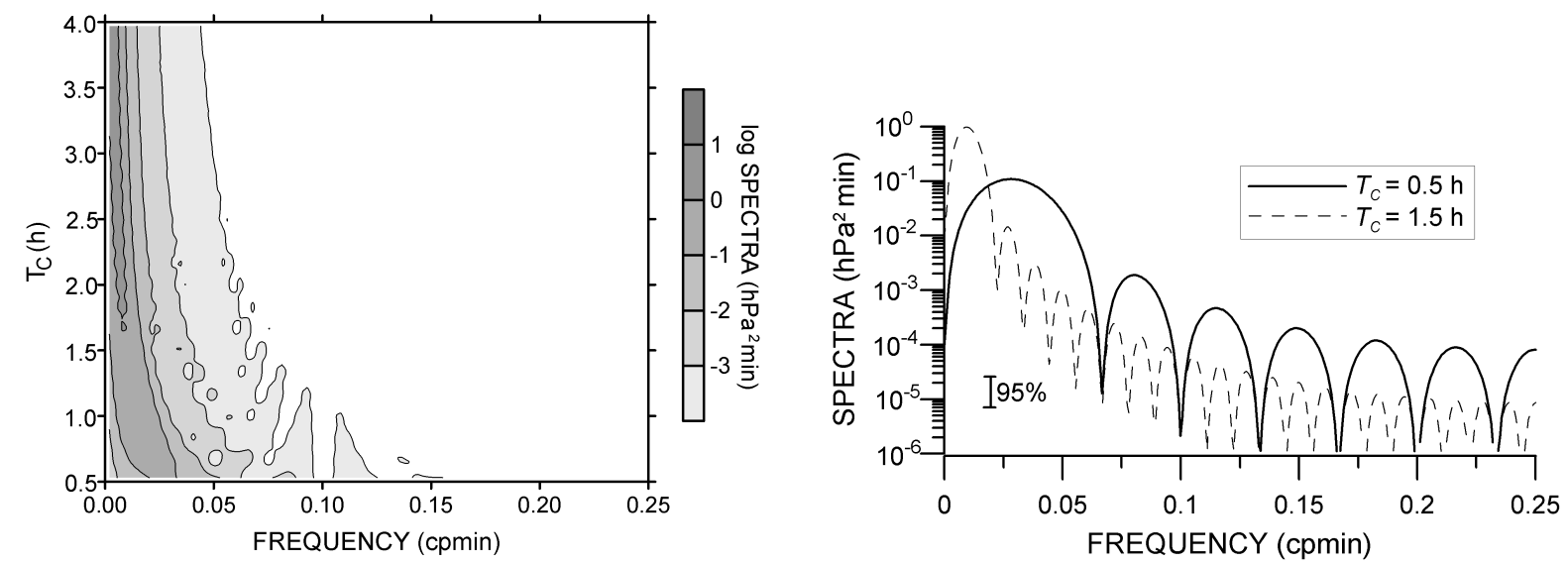

Fig. 4. Power spectra of eulerian air pressure series versus cosine disturbance period $T_{C}\left(A_{C}=3 \mathrm{hPa}, V_{C}=20 \mathrm{~m} / \mathrm{s}\right)$.

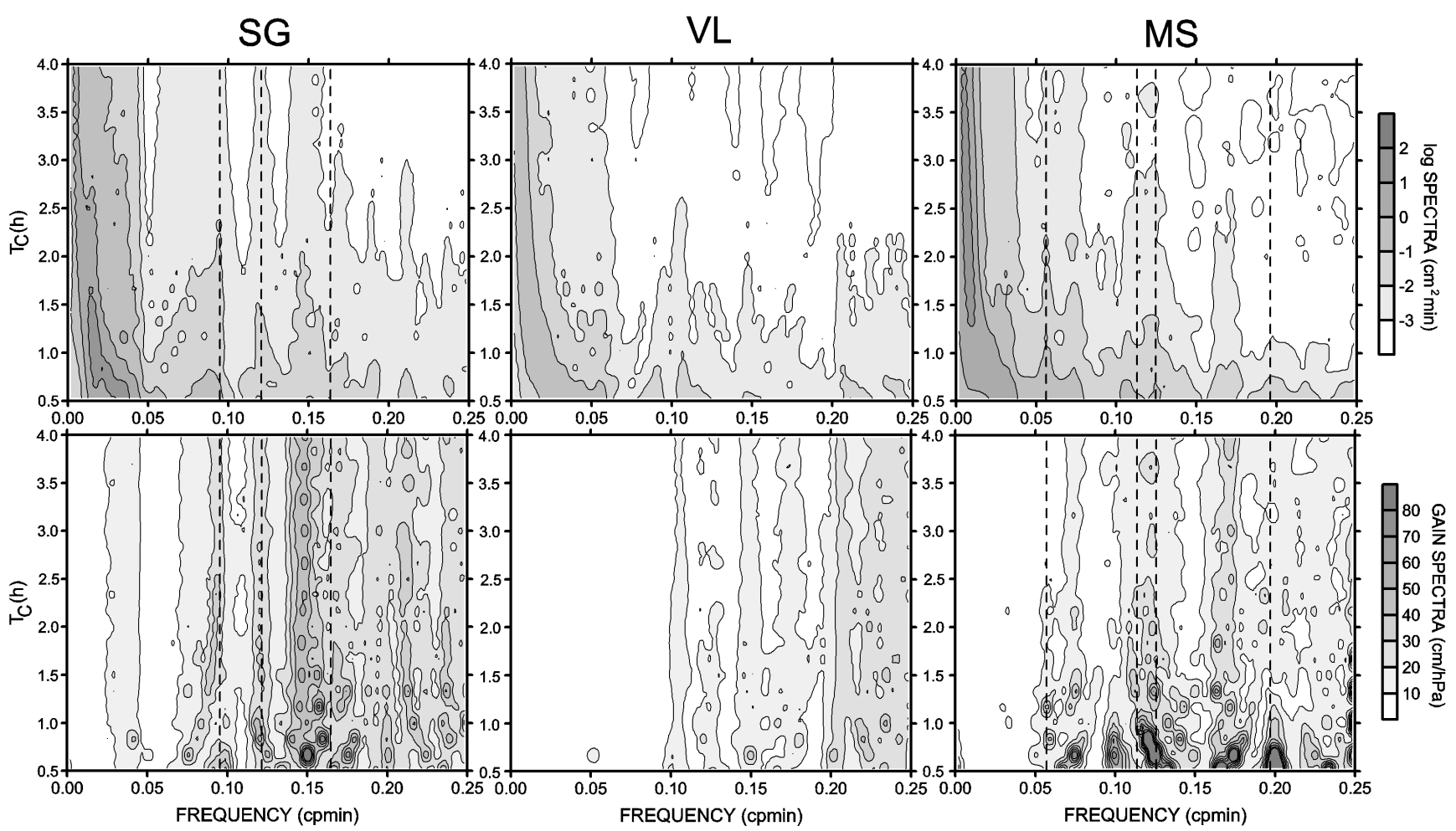

Fig. 5. Power spectra (upper) and gain spectra (lower) of sea level series modelled at the SG, VL and MS grid points versus cosine disturbance period $T_{C}\left(A_{C}=3 \mathrm{hPa}, V_{C}=20 \mathrm{~m} / \mathrm{s}\right)$. Natural periods of Stari Grad and Mali Ston Bays are indicated by dashed lines (after Vilibić et al., 2004).

single point). Both $T_{C}$ and $T_{B}$ may be used for the computation of disturbance wavelength, which in our case ranges from $36 \mathrm{~km}$ (period of $0.5 \mathrm{~h}$ ) to $432 \mathrm{~km}$ (period of $4 \mathrm{~h}$ ). In addition, the linearity of the response regarding the intensity of a disturbance will be checked by setting $T_{C}$ to constant and varying $A_{C}$, whereas the sensitivity of various bays to the disturbance speed will be tested by setting $T_{C}$ to a constant value and varying the disturbance speed $V_{C}$, as different topographic characteristics (various depths) are in front of the investigated bays, presumably resulting in different amplification rates generated by the Proudman resonance.

\section{The results}

\subsection{Cosine disturbance}

The spectral shape of Eulerian time series of travelling cosine disturbance is already documented by Vilibić et al. (2005). Spectral maximum is positioned on the cosine period, whereas the energy is cycloidally decreasing towards the higher frequencies (cycloid shape is due to the finite length of the analyzed series). Energy peak at the dominant frequency is more pronounced when enlarging the 

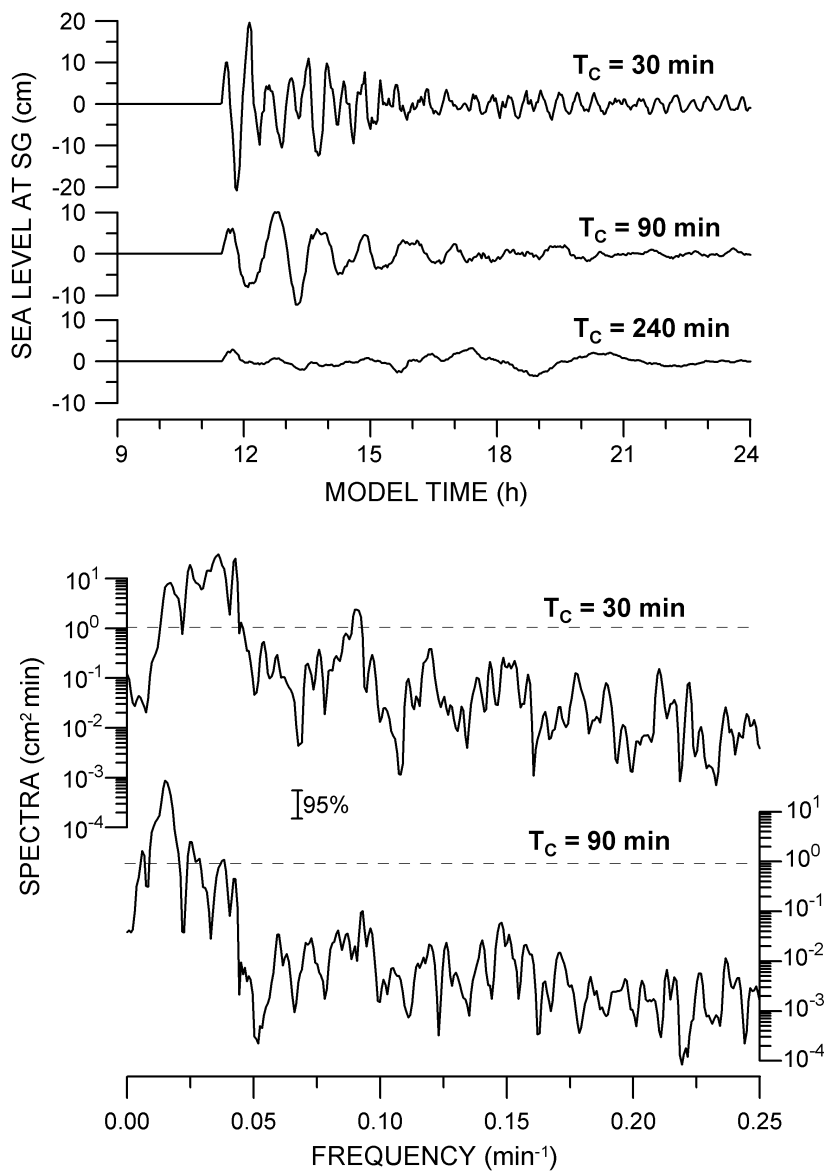

Fig. 6. Modelled sea level series (upper) and corresponding spectra (lower) at the $\mathrm{SG}$ grid point for $T_{C}$ equal to 30,90 and $240 \mathrm{~min}$ $\left(A_{C}=3 \mathrm{hPa}, V_{C}=20 \mathrm{~m} / \mathrm{s}\right)$.

disturbance period $T_{C}$ (Fig. 4), in contrast to the energy at higher frequencies, which is larger for the shorter $T_{C}$.

Such spectral characteristics of the forcing mechanism result in similar spectral characteristics of the ocean waves when no topographic constraints are considered. However, the Middle Adriatic coastal waters possess very complex topography, and a number of natural oscillations are excited by a broad-band forcing mechanism. At the SG grid point (Fig. 5) in front of Stari Grad Bay, the maximum of energy is positioned around the main disturbance period, but the energy transfer is more efficient for shorter $T_{C}$, with a gain of about $15 \mathrm{~cm} / \mathrm{hPa}\left(T_{C}=0.5 \mathrm{~h}, f=1 / T_{C}\right)$. The gain is considered here as a ratio between sea level and air pressure in each frequency band, having its static (inverse barometric) value of $-1 \mathrm{~cm} / \mathrm{hPa}$ (only absolute values will be considered in the following). The gain decreases to about $2.5 \mathrm{~cm} / \mathrm{hPa}$ for $T_{C}=1.5 \mathrm{~h}$ and $f=1 / T_{C}$, and to about $1.1 \mathrm{~cm} / \mathrm{hPa}$ for $T_{C}=4.0 \mathrm{~h}$ and $f=1 / T_{C}$, having a tendency towards the inverse barometric sea response to the atmospheric disturbance. A significantly lower energy transfer rate may be found for shorter $T_{C}$ in front of Vela Luka $\left(3 \mathrm{~cm} / \mathrm{hPa}\right.$ for $T_{C}=0.5 \mathrm{~h}$ and $\left.f=1 / T_{C}\right)$ and a bit higher at Mali Ston $(7 \mathrm{~cm} / \mathrm{hPa}$ for $T_{C}=0.5 \mathrm{~h}$ and $\left.\mathrm{f}=1 / T_{C}\right)$. Oppositely, a larger gain value
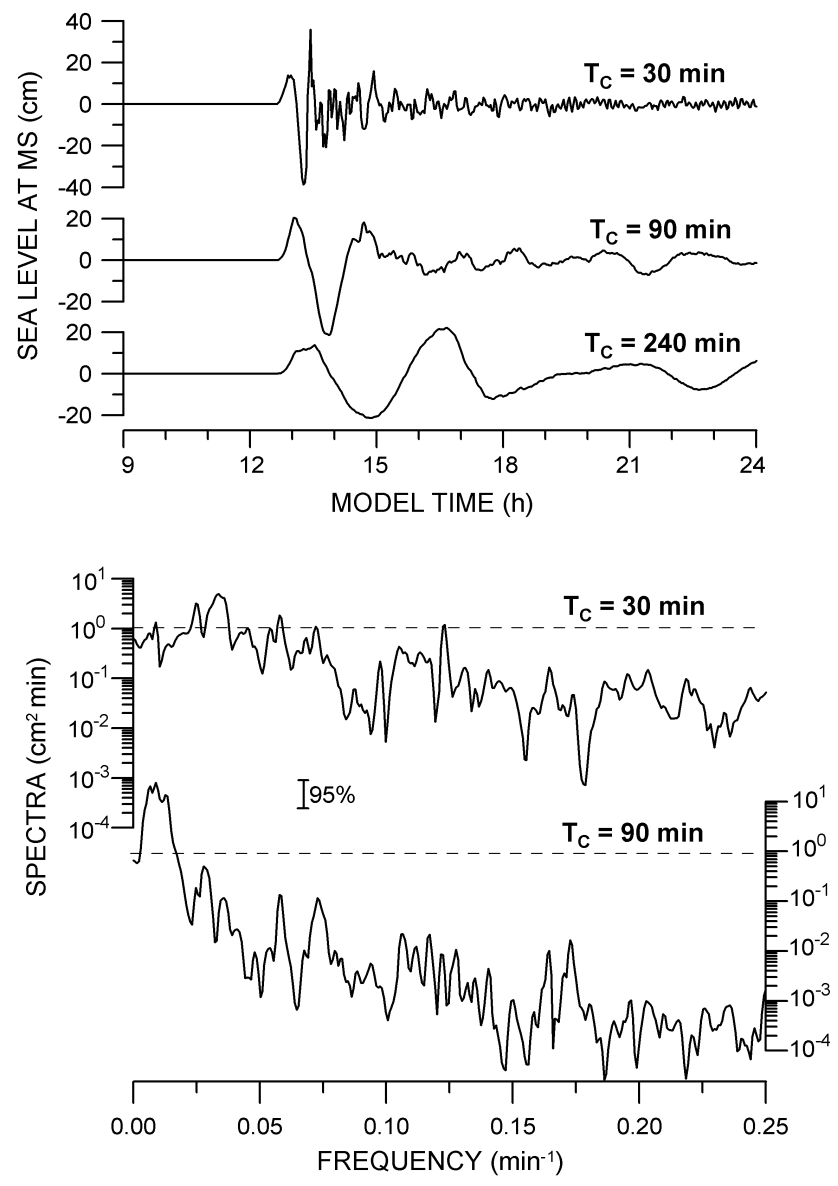

Fig. 7. As in Fig. 5, but at the MS grid point.

may be found for longer $T_{C}$ at MS (about $3.5 \mathrm{~cm} / \mathrm{hPa}$ for $T_{C}=4.0 \mathrm{~h}, \mathrm{f}=1 / T_{C}$ ), which is the result of more efficient energy transfer due to the natural period of the whole area, which is around $4 \mathrm{~h}$ (Vilibić et al., 2005).

Although sea level oscillations at $0.5 \mathrm{~h}$ or a larger period may be significant in the basin, even comparable with the tides due to free oscillations of the whole basin (Vilibic et al., 2005), harbour resonance in smaller bays occurs at shorter periods. Vilibić et al. (2004) estimated the most significant natural oscillations at the Stari Grad (10.6, 8.3, $6.1 \mathrm{~min})$ and Mali Ston Bays (17.7, 8.8, 8.0, 5.1 min). However, all of Stari Grad Bay is exposed to the incoming waves, whereas this is not the case for Mali Ston Bay, which has two narrow constrictions reflecting a great part of the incoming waves. The result is almost no amplification of the sea level inside Mali Ston Bay, but the currents are really vigorous at the constrictions.

Generally, the most efficient energy transfer occurs when the energy of the incoming waves in front of a bay coincide with the natural bay periods. At the SG grid point (i.e. in front of Stari Grad Bay), a strip of enlarged energy may be found at $0.15 \mathrm{cpmin}(6.7 \mathrm{~min})$ and $0.09 \mathrm{cpmin}(11 \mathrm{~min})$ (Figs. 5 and 6), which are close to the natural oscillations of Stari Grad Bay (6.1 and $10.6 \mathrm{~min}$ ). In fact, the peak at 

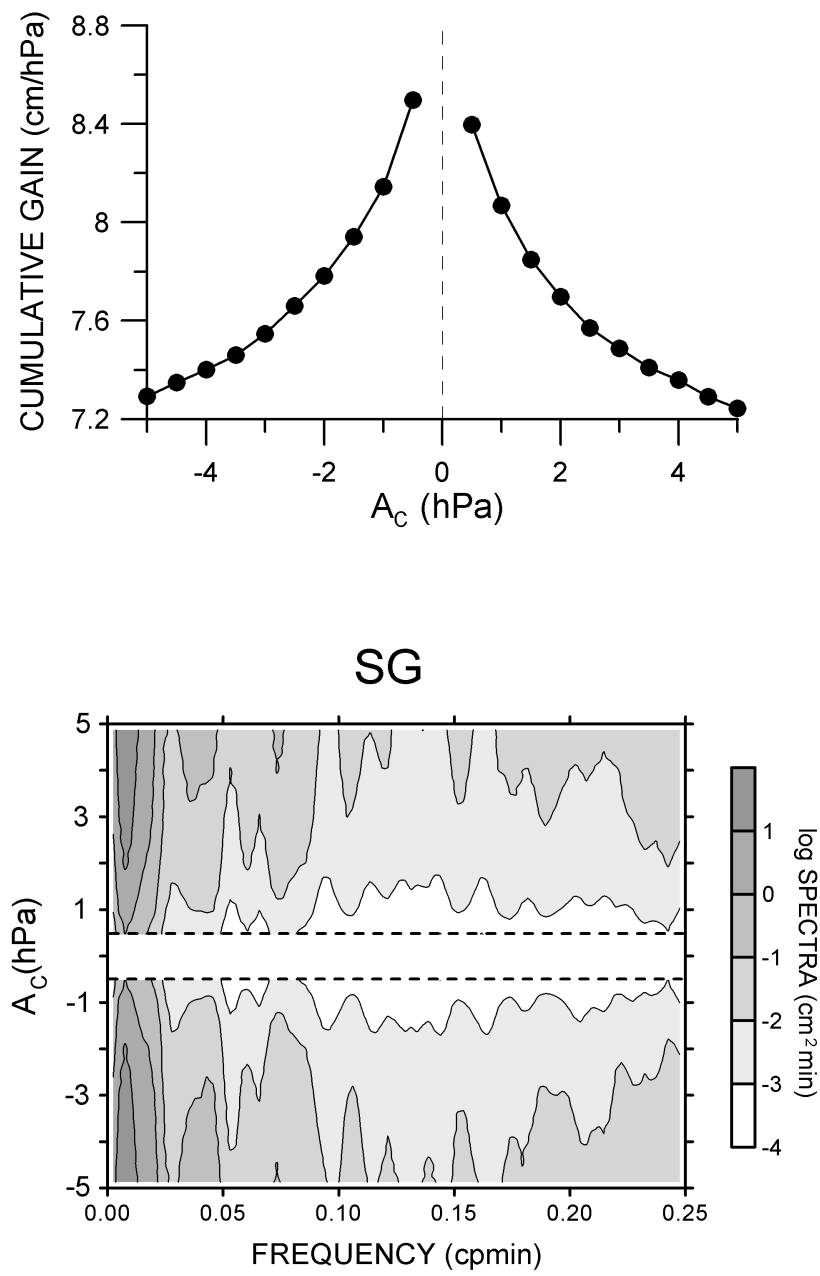

Fig. 8. Cumulative gain versus cosine disturbance amplitude $A_{C}$ (upper panel), and spectra of sea level series modelled at SG for the same range of $A_{C}$ (bottom panel). $T_{C}$ is set to $80 \mathrm{~min}$ and $V_{C}$ to $20 \mathrm{~m} / \mathrm{s}$. Cumulative gain is defined as the square root of the cumulative sea level over cumulative air pressure energy.

$6.1 \mathrm{~min}$ is the natural period of the inner basin (Stari Grad Harbour, Vilibić et al., 2004), which was the most affected area during the June 2003 flood. Therefore, the flooding of the Stari Grad city is presumably excited by the incoming waves at the near-natural bay/harbour frequency, which are generated topographically in front of Stari Grad Bay by the harbour resonance effect and then propagated into the bay and Stari Grad Harbour. The amplification rate at the SG point and on $1 / f=6.7 \mathrm{~min}$ is modelled to be between 30 and $50 \mathrm{~cm} / \mathrm{hPa}$ for all $T_{C}$, being more energetic for the shorter $T_{C}$ due to higher energy of the forcing disturbance. A similar effect takes place for the 10.6-min seiche, which is obviously a result of the 11-min resonant oscillation generated in the region off Stari Grad Bay.

The energy at the VL grid point is a few times smaller than at the SG point, presumably due to higher depths in front of the bay (about $100 \mathrm{~m}$; this hypothesis will be tested in Sect. 3.4), which falls far from the Proudman reso- nance equilibrium depth ( $40 \mathrm{~m}$ for the disturbance speed of $20 \mathrm{~m} / \mathrm{s}$ ). Therefore, the energy at all frequency bands compared to SG is lower (Fig. 5), and the gain doesn't surpass $30 \mathrm{~cm} / \mathrm{hPa}$. Yet, the gain at VL is the largest at high frequencies $(>0.20 \mathrm{cpmin})$, yielding to the conclusion that shortlasting atmospheric disturbances (a period of a few minutes) are presumably more favourable for the generation of harbour resonance in Vela Luka Bay.

A bit of a different situation is in front of Mali Ston Bay (MS grid point, Figs. 5 and 7), where the largest energies are modelled at low frequencies, but for a longer disturbance period $T_{C}$. As said, it is presumably due to the energy transfer towards the fundamental mode of the whole coastal area (period of $4 \mathrm{~h}$ ), which was also discussed by Vilibić et al. (2005) in light of the different disturbance shapes and energy distributions. Large energy is also modelled for short $T_{C}$, and the gain may surpass $100 \mathrm{~cm} / \mathrm{hPa}$ for some frequencies (e.g. at $0.12-0.13 \mathrm{cpmin}$ and $0.20 \mathrm{cpmin}$ ). Such oscillations may result primarily in vigorous currents in two major constraints inside Mali Ston Bay, as a part of the incoming waves are reflected from the narrow bay mouth (Vilibić et al., 2004) and a part of it is canalised through the constraints. An event in June 2003 resulted in currents exceeding $100 \mathrm{~cm} / \mathrm{s}$, but severe events are also reported occasionally by the local authorities and people (Hydrographic Institute, 2003).

Finally, the linearity of the model response to the different intensity of the disturbance has been tested by the changing cosine amplitude $A_{C}$ from -5 to $5 \mathrm{hPa}$, and by keeping the period $T_{C}$ at $80 \mathrm{~min}$ (real value taken from the measurements). One may see that a larger gain is reached for the lower $A_{C}$ (Fig. 8), but only up to $15 \%$, which is not a large variability regarding large changes in air pressure amplitude (order of magnitude). It seems that such small changes in gain are predominantly driven by bottom friction which increases with $A_{C}$, while the sea level response may be considered as near-linear and near-symmetric in the SG area regarding the disturbance intensity. The same conclusions may be reached for the MS and VL grid points, and also for box-like disturbances (see the next section).

\subsection{Box disturbance}

Spectral characteristics of a box disturbance show some similarities but also differences to the cosine variation (Fig. 9). The maximum of the energy is reached at very low frequencies, not at the disturbance period/duration of the cosine disturbance. However, a cycloidal decrease in energy is kept when going towards higher frequencies (cycloid shape is again due to a finite length of the analyzed series), but with a significantly lower rate, as the energy is larger there than for the cosine disturbance, especially for the longer disturbance duration $\left(T_{B}\right)$ versus the same cosine period $\left(T_{C}\right)$.

The acting of such a disturbance results in significantly higher sea level energy in the high frequency domain (Fig. 10). Again, a band of enlarged gain may be seen at the SG grid point around 0.15 and $0.09 \mathrm{cpmin}$, and a larger gain at higher frequencies at the VL grid point, depicting 

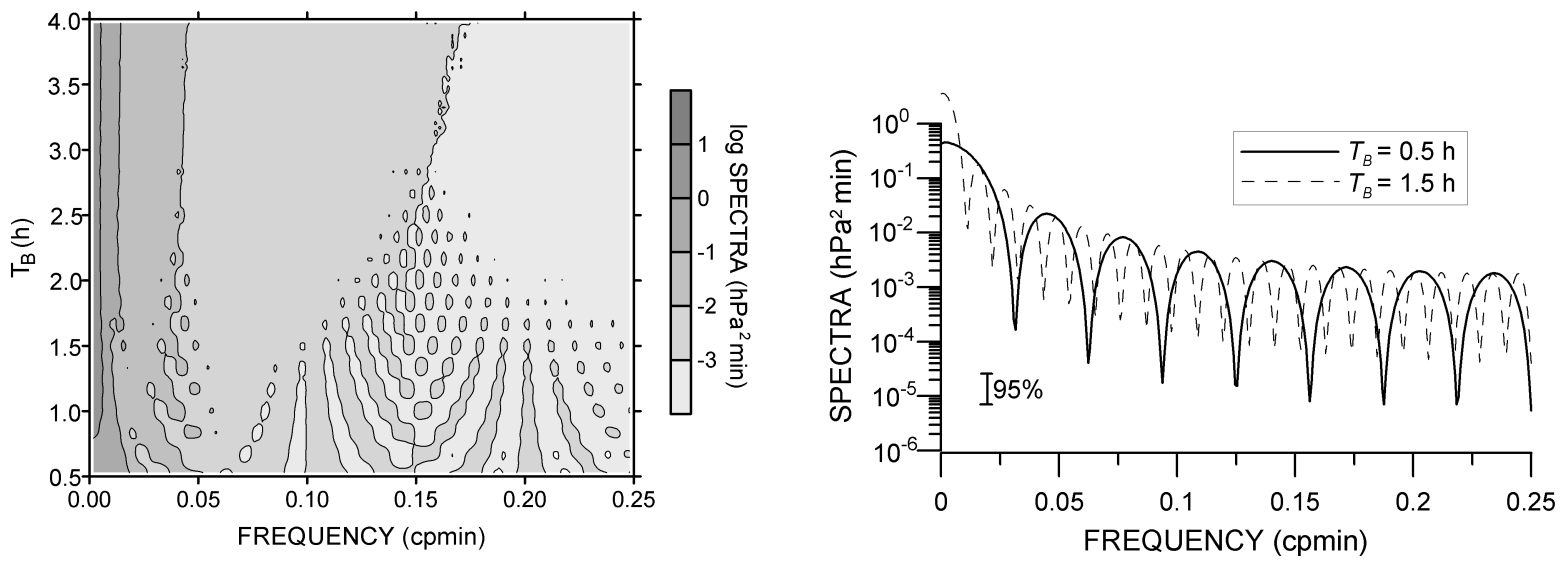

Fig. 9. Power spectra of eulerian air pressure series versus box disturbance duration $T_{B}\left(A_{B}=3 \mathrm{hPa}, V_{B}=20 \mathrm{~m} / \mathrm{s}\right)$.

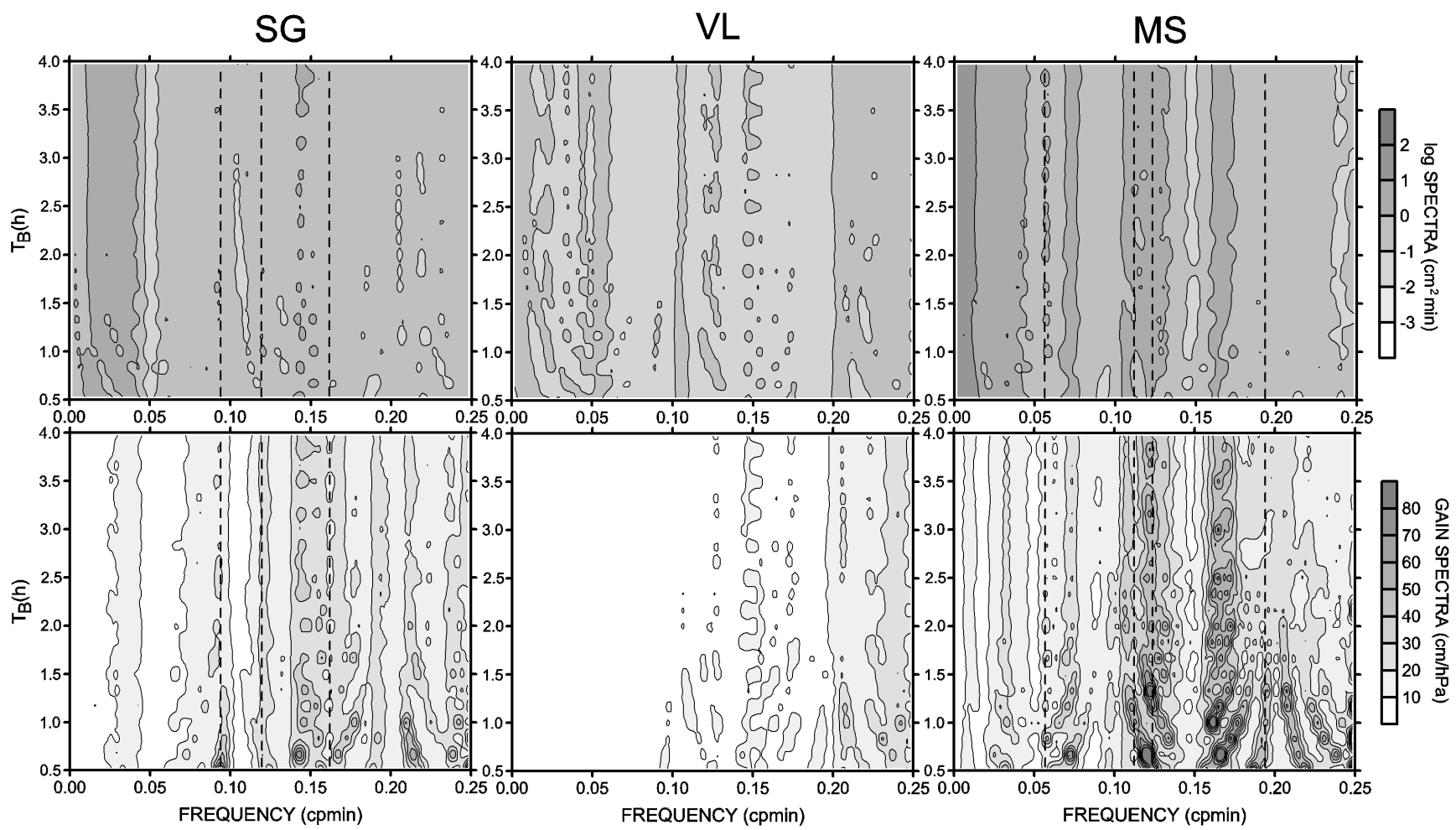

Fig. 10. Power spectra (upper) and gain spectra (lower) of sea level series modelled at the SG, VL and MS grid points versus box disturbance duration $T_{B}\left(A_{B}=3 \mathrm{hPa}, V_{B}=20 \mathrm{~m} / \mathrm{s}\right)$. Natural periods of Stari Grad and Mali Ston Bays are indicated by dashed lines (after Vilibić et al., 2004).

harbour resonance that is appearing in the area. A larger gain is modelled for the MS grid point, especially at the two frequency bands of 0.12 and $0.16-0.17$ cpmin, which are presumably responsible for the energy transfer towards some natural modes of Mali Ston Bay. The energy is varying a little by changing $T_{B}$ in the whole basin, as the energy content of the box disturbance is predominantly defined by the rate/amplitude of the air pressure step rather than the disturbance duration - a drop in air pressure back to normal values is just another step function acting in contrast to the first one.
This characteristic is visible at the sea level series (e.g. at the MS grid point, Fig. 11), where the energy content at high frequencies is not decreasing by changing $T_{B}$. However, some changes appear at very low frequencies, where higher $T_{B}$ values result in larger energies. In particular, the energy may be significant at the fundamental 4-h basin seiche mode, which is recognized to be excited by a travelling box disturbance rather than a cosine disturbance (Vilibić et al., 2005). 

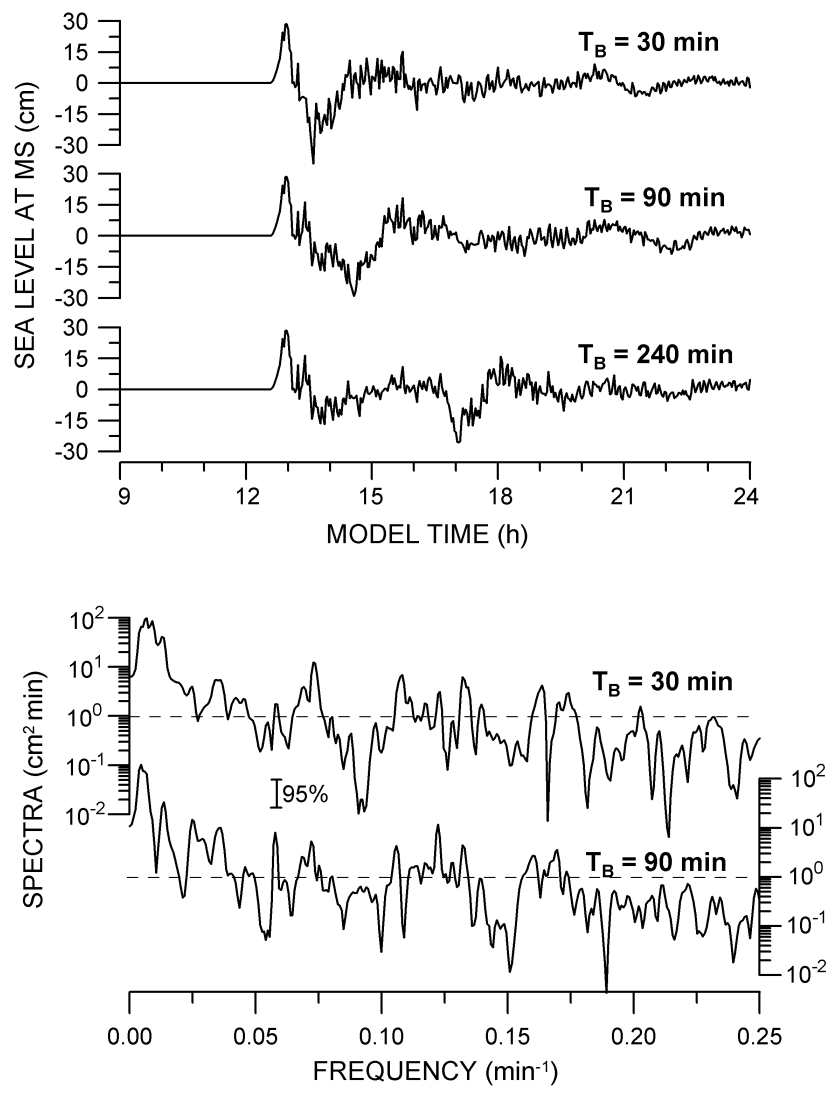

Fig. 11. Modelled sea level series (upper) and corresponding spectra (lower) at the $\mathrm{SG}$ grid point for $T_{B}$ equal to 30,90 and $240 \mathrm{~min}$ $\left(A_{B}=3 \mathrm{hPa}, V_{B}=20 \mathrm{~m} / \mathrm{s}\right)$.

\subsection{Variable disturbance speed}

All of the three examined bays (Stari Grad, Vela Luka and Mali Ston) are situated in different topographic encirclements with various depths in front of them. Therefore, a different response is expected to occur on the travelling atmospheric disturbance, at least for the short-lasting ones, i.e. for low $T_{C}$ and $T_{B}$ values, whose wavelengths are comparable to the resonance generation area. A cosine travelling disturbance with $T_{C}=30 \mathrm{~min}$ is therefore used to test such a hypothesis (again propagating eastward along the model domain), while the disturbance speed $V_{C}$ is varied from 10 to $40 \mathrm{~m} / \mathrm{s}$ (resonance depths from 10 to $160 \mathrm{~m}$ ).

The frequency-domain response at the SG, VL and MS grid points is given in Fig. 12. One can see that the largest energies at $S G$ occur from 20 to $25 \mathrm{~m} / \mathrm{s}$ for the periods higher than $20 \mathrm{~min}(0.05 \mathrm{cpmin})$. However, energy maximum is shifting towards larger $V_{C}$ when increasing the frequency, with a maximum around $27 \mathrm{~m} / \mathrm{s}$ at $0.09 \mathrm{cpmin}(11 \mathrm{~min})$ and around $25 \mathrm{~m} / \mathrm{s}$ at $0.15 \mathrm{cpmin}(6.7 \mathrm{~min})$. Therefore, a single cosine disturbance results in a variety of resonance depths, being shallower for its low-frequency part at SG and vice versa.

A different distribution is modelled for the VL point; there are two maxima at $V_{C}$ of 26 and $30 \mathrm{~m} / \mathrm{s}$ for frequencies lower

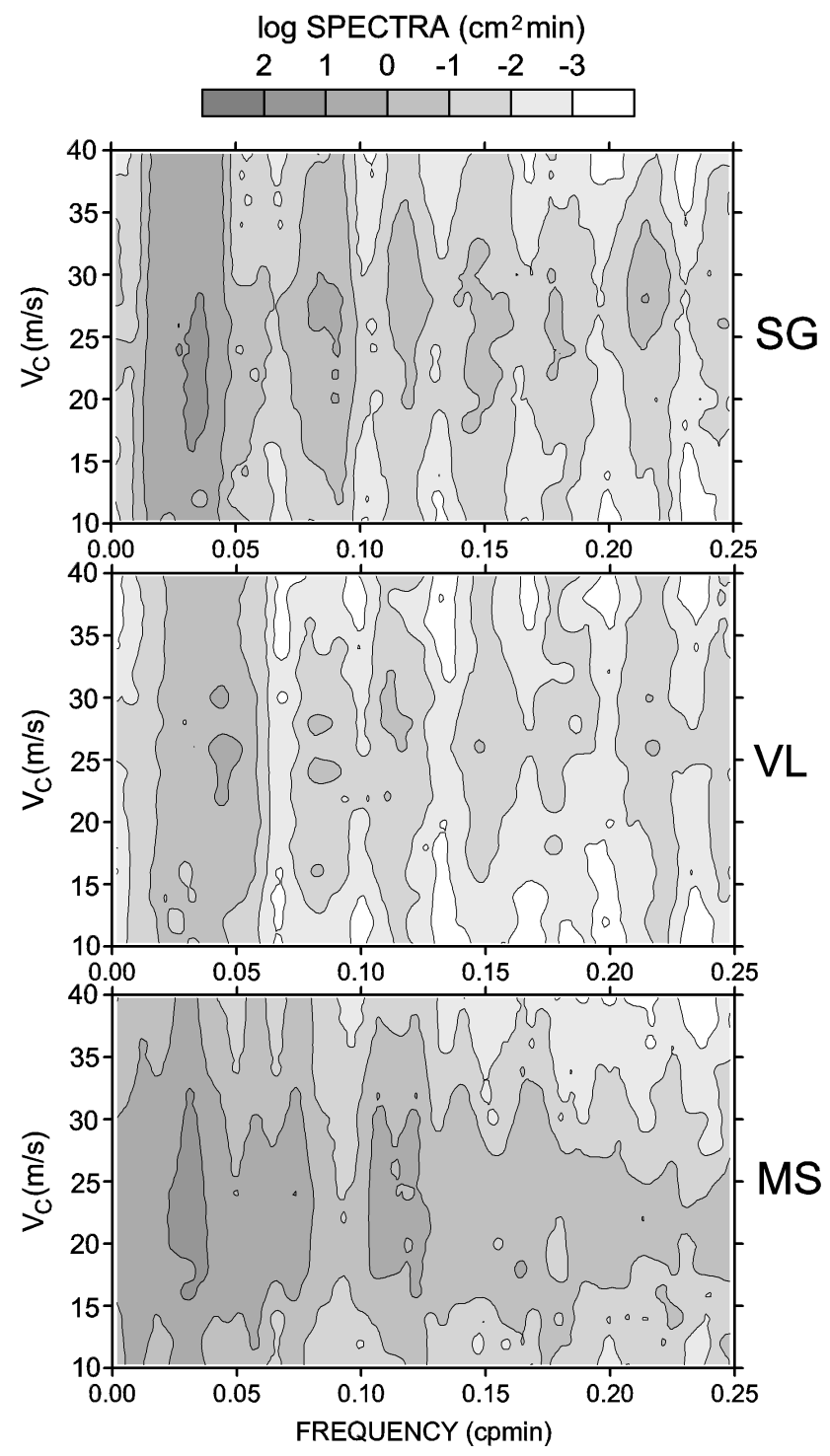

Fig. 12. Power spectra of sea level series at SG, VL and MS grid points versus disturbance speed $V_{C}\left(T_{C}=30 \mathrm{~min}, A_{C}=3 \mathrm{hPa}\right)$.

than $0.2 \mathrm{cpmin}$. The maxima are also located for $V_{C}$ between 25 and $30 \mathrm{~m} / \mathrm{s}$ at higher frequencies, but again, with two or more maxima at a single frequency band. This may be a result of the variable depth in front of Vela Luka Bay, as the bottom has a slope perpendicular to the disturbance direction, what is not the case off Stari Grad Bay.

Finally, the energy at the MS grid point has a maximum for $V_{C}$ of $22-24 \mathrm{~m} / \mathrm{s}$ at all frequencies. As the depths are about 25-30 m west from the MS grid point, it seems that the Proudman resonance is not happening there, but more to the northwest, towards the deeper areas. The maximum at the main period $(30 \mathrm{~min})$ is reached at a $V_{C}$ of $22-24 \mathrm{~m} / \mathrm{s}$ (resonance depth of about $50 \mathrm{~m}$ ), being equivalent to a wavelength of around $40 \mathrm{~km}$. Therefore, the resonance is presumably occurring at about $40 \mathrm{~km}$ WNW from the MS grid point (around the eastern cape of the island of Hvar), where a plateau with 
depths between 45 and $55 \mathrm{~m}$ is situated and the resonance is suspected to occur in June 2003 (Vilibić et al., 2004). After the generation, the waves are topographically enlarged (decrease in depth and channel width) and directed towards the entrance of Mali Ston Bay.

Total energy content at the SG, VL and MS grid points (Fig. 13) denotes the efficiency of the resonant coupling and other effects which derive a sea level versus different disturbance speed $V_{C}$. The energy is generally largest at the MS point, which is presumably the result of an additional topographical enlargement plus the resonant energy transfer. Such a topographical effect is significantly lower at the SG point, but it becomes visible for the larger $V_{C}$, where the energy content at SG surpasses the energy content at MS. It follows that the resonance is appearing at larger depths $(\sim 100 \mathrm{~m})$ which are close to the western edge of the model domain. Once generated there, it is enlarged due to shallowing towards the Stari Grad Bay. Maximum energy content is placed at $22 \mathrm{~m} / \mathrm{s}$, at both the SG and MS grid points, denoting such speed as the most efficient for the energy transfer in that area. Nevertheless, it seems that this is not the case at the $\mathrm{VL}$ point, where energy maximum is positioned at $V_{C}$ of $26 \mathrm{~m} / \mathrm{s}$, although a few times lower than at the MS and SG points. In addition, secondary maxima are visible at 24 and $30 \mathrm{~m} / \mathrm{s}$, presumably due to the transversal bottom slope effects, as stated when discussing the energy content modelled in the frequency-domain (Fig. 12). It is interesting to notice that the response of the two affected areas relatively close to each other (Stari Grad and Vela Luka Bays) is dependent on the disturbance speed, which may be one of the factors that causes the flood only in one bay and not in the other (Vela Luka but not Stari Grad is flooded in June 1978, and oppositely in June 2003). However, additional effects may take place, such as the disturbance propagating direction, as well as the channelling effects inside the bays.

\section{Summary and conclusions}

This study was triggered by the flood of Stari Grad in June 2003, which put into focus rare but vigorous events that occured in the Middle Adriatic coastal waters. Vilibić et al. (2004) related the phenomenon to the double resonance (Proudman and harbour) plus a topographical effect, being excited by a cosine-like travelling disturbance propagating eastward over the area. Vilibić et al. (2005) documented a similar event in August 2004 which resulted in no flooding. The latter was excited by a box travelling disturbance coupled with moderate to severe winds, which resulted in a different frequency distribution of the sea level energy. The influence of the wind was also acknowledged, although being a secondary effect. Both events were excited by a disturbance having a similar major period/duration of about 80 $90 \mathrm{~min}$, which defined one of the problems that we attempted to solve in this work: how do the changes in the disturbance period affect the sea response? Such a problem is examined by barotropic numerical modelling, forced with an air pres-

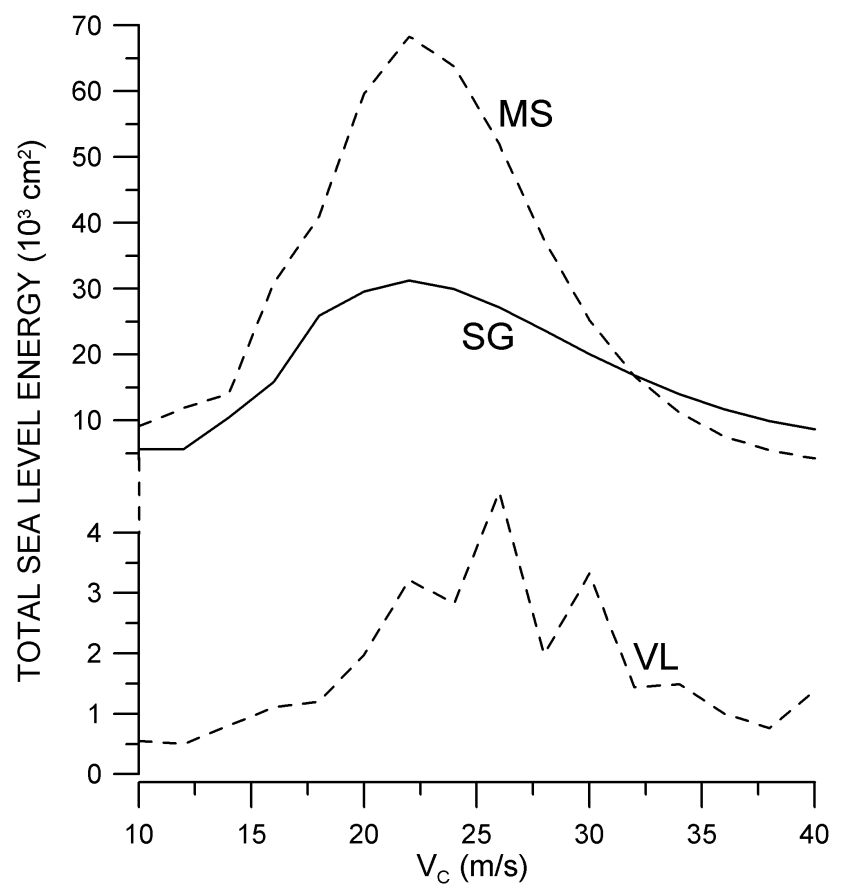

Fig. 13. Total energy content of sea level series at the SG, VL and MS grid points versus disturbance speed $V_{C} \quad\left(T_{C}=30 \mathrm{~min}\right.$, $\left.A_{C}=3 \mathrm{hPa}\right)$.

sure travelling disturbance only, and by examining a sea level series and spectra in front of three most affected areas.

Another issue examined here is the impact of the different shapes of travelling disturbances to the sea, while a third question arose from the different responses at Vela Luka and Stari Grad Bays documented from the past events. In other words, What is the sensitivity of the region to the various disturbance speeds? The following conclusions may be drawn from the results:

- Sea level energy in a high-frequency domain is increasing with the decreasing of a Eulerian disturbance period/duration (i.e. with the disturbance wavelength) due to short (a few tens of $\mathrm{km}$ ) length scales of the Proudman resonance generation areas. The resonance is efficiently occurring at certain depths only (resonance depth is about $40 \mathrm{~m}$ for the disturbance speed of $20 \mathrm{~m} / \mathrm{s})$. Therefore, extreme events and flooding in the affected bays are favoured with short and intense atmospheric gravity waves, as they match natural frequencies of the corresponding bays/harbours. Oppositely, lowfrequency natural modes of the whole area (fundamental at $4 \mathrm{~h}$ and higher ones) favour longer atmospheric disturbances, but the energy transfer towards the sea (resonance amplification) is significantly lower due to a large length scale compared to the resonance areas.

- Regular travelling box disturbances possess significantly larger high-frequency energy than cosine disturbances. This means that box disturbances should be 
more efficient in the generation of both Proudman and harbour resonances. Although abrupt pressure changes are common in nature (e.g. on frontal lines, squalls, gusts), no regular box function with an instantaneous air pressure step and sharp box edges may occur in nature, which significantly decreases the amount of highfrequency energy, as observed in August 2004 (Vilibić et al., 2005).

- The amplification rate (gain) in front of the affected bays is defined by the local topography. At some frequencies (e.g. at $0.15 \mathrm{cpmin}$ at Stari Grad Bay) its absolute values may surpass 50 or even $100 \mathrm{~cm} / \mathrm{hPa}$. If such a frequency coincides or is close to the natural periods of a bay (e.g. at 0.16 cpmin at Stari Grad Bay), harbour resonance may be quite energetic, resulting in strong floods of the inner bay areas.

- Different topographic characteristics (different depths) in front of Stari Grad and Vela Luka Bays results in various resonance efficiency for various disturbance speeds. Maximum energy is reached for the speed of $22 \mathrm{~m} / \mathrm{s}$ off Stari Grad and $26 \mathrm{~m} / \mathrm{s}$ off Vela Luka, which may partially explain a lack of coincidence in observed floods. Yet other factors contribute to that, such as the difference in energy content of a real air pressure series, the difference in bay shapes (Stari Grad Bay is channel-like whereas Vela Luka Bay is cone-like) and the different directions of the disturbance propagation, which will be topic of future investigations.

Acknowledgements. The 2DD numerical model was developed by K. Black and was kindly provided from ASR Ltd., New Zealand, with assistance of N. Domijan. M. Orlić provided bathymetry file used in the model. The Ministry of Science, Education and Sport of the Republic of Croatia supported the research through grants 0001001 and 0119330.

Topical Editor N. Pinardi thanks A. B. Rabinovich and two other referees for their help in evaluating this paper.

\section{References}

Black, K. P.: The Numerical Hydrodynamic Model 3DD1 and Support Software, Department of Earth Sciences, University of Waikato, New Zealand, Occasional Report No. 19, 1995.

Candela, J., Mazzola, S., Sammari, C., Limeburner, R., Lozano, C. J., Patti, B., and Bonnano, A.: The "Mad Sea" phenomenon in the Strait of Sicily, J. Phys. Ocea., 29, 2210-2231, 1999.

Defant, A.: Physical Oceanography, Pergamon, Oxford, 1961.

Donn, W. L.: The Great Lakes storm surge of May 5, 1952, J. Geophys. Res., 64(2), 191-198, 1959.

Dragani, W. C., Mazio, C. A., and Nuñez, M. N.: Sea level oscillations in coastal waters of the Buenos Aires province, Argentina, Continental Shelf Research, 22, 779-790, 2002.
Garcies, M., Gomis, D., and Monserrat, S.: Pressure-forced seiches of large amplitude in inlets of the Balearic Islands - 2 - Observational study, J. Geophys. Res., 101(C3), 6453-6467, 1996.

Gomis, D., Monserrat, S., and Tintore, J.: Pressure-forced seiches of large amplitude in inlets of the Balearic Islands, J. Geophys. Res., 98(C8), 14437-14445, 1993.

Herak, M., Orlić, M., and Kunovec-Varga, M.: Did the Makarska earthquake of 1962 generate a tsunami in the central Adriatic archipelago?, J. Geodyn., 31, 71-86, 2001.

Hibiya, T. and Kajiura, K.: Origin of the Abiki phenomenon (a kind of seiche) in Nagasaki Bay, Journal of the Oceanographical Society of Japan, 38, 172-182, 1982.

Hodžić, M.: Occurrences of exceptional sea-level oscillations in the Vela Luka Bay (in Croatian), Priroda, 68(2-3), 52-53, 1980.

Hydrographic Institute: Pilot for Small Ships and Boats (in Croatian), Vol. 2, Hydrographic Institute of the Republic of Croatia, Split, 2003.

Liu, P. L.-F., Monserrat, S., and Marcos, M.: Analytical simulation of edge waves observed around the Balearic Islands, Geophys. Res. Lett., 29(17), 1847, doi:10.1029/2002GL015555, 2002.

Liu, P. L.-F., Monserrat, S., Marcos, M., and Rabinovich, A. B.: Coupling between two inlets: Observation and modeling, J. Geophys. Res., 108(C3), 3069, doi:10.1029/2002JC001478, 2003.

Mercer, D., Sheng, J., Greatbatch, R. J., and Bobanović, J.: Barotropic waves generated by storms moving rapidly over shallow water, J. Geophys. Res., 107(C10), 3152, doi:10.1029/2001JC001140, 2002.

Monserrat, S., Ibbetson, A., and Thorpe, A. J.: Atmospheric gravity waves and the "Rissaga" phenomenon, Q. J. Royal Meteor. Soc., 117, 553-570, 1991.

Monserrat, S., Rabinovich, A. B., and Casas, B.: On the reconstruction of the transfer function for atmospherically generated seiches, Geophys. Res. Lett., 25(12), 2197-2200, 1998.

Orlić, M.: About a possible occurrence of the Proudman resonance in the Adriatic, Thalassia Jugoslavica, 16(1), 79-88, 1980.

Proudman, J.: The effects on the sea of changes in atmospheric pressure, Geophysical Supplement to the Monthly Notices of the Royal Astronomical Society, 2(4), 197-209, 1929.

Rabinovich, A. B.: Long Ocean Gravity Waves: Trapping, Resonance and Leaking (in Russian), Gidrometeoizdat, St. Petersburg, 1993.

Rabinovich, A. B. and Monserrat, S.: Generation of meteorological tsunamis (large amplitude seiches) near the Balearic and Kuril Islands, Nat. Hazards, 18, 27-55, 1998.

Rabinovich, A. B., Monserrat, S., and Fain, I. V.: Numerical modelling of extreme seiche oscillations in the region of the Balearic Islands, Oceanology, 39(1), 12-19, 1999.

Tintore, J., Gomis, D., Alonso, S., and Wang, D. P.: A theoretical study of large sea level oscillations in the Western Mediterranean, J. Geophys. Res., 93(C9), 10 797-10 803, 1988.

Vilibić, I., Domijan, N., Orlić, M., Leder, N., and Pasarić, M.: Resonant coupling of a traveling air-pressure disturbance with the east Adriatic coastal waters, J. Geophys. Res., 109, C10001, doi:10.1029/2004JC002279, 2004.

Vilibić, I., Domijan, N., and Čupić, S.: Wind versus air pressure seiche triggering in the Middle Adriatic coastal waters, J. Marine Syst., 57, 189-200, 2005. 